\title{
Strategi Pengembangan Daya Tarik Wisata Bukit Gundaling Di Kabupaten Karo
}

Ruth Purnama Natalie Gintinga,1, Ida Bagus Suryawana,2

1utthegtg@gmail.com, 2idabagussuryawan@unud.ac.id

a Program Studi S1 Destinasi Pariwisata, Fakultas Pariwisata,Universitas Udayana, Jl. Dr. R. Goris, Denpasar, Bali 80232 Indonesia

\section{Abstract}

Gundaling Hill is a tourist attraction located in the city of Berastagi Karo. The Hill is known as natural tourist attraction since the Dutch colonial era, and has a unique history that makes it more attractive for tourist who visit it. However, Gundaling Hill is no longer attractive for tourist. It is because there is no development on it, and there are some new tourist attractions are established which have replaced the position of Gundaling Hill as a famous tourist attraction in Karo. The research purposes are; to determine the potential of the tourist attraction Gundaling Hill and to determine what needs to be done for the development of Gundaling Hill. This study uses qualitative research methods and the concept of tourism potential and tourism development. Over time Gundaling Hill no longer as beautiful and as well-known as earlier, it is because there is no development is done to the charms of this site, so that tourist no longer feel that Gundaling Hill is a wonderful tourist attraction. The reason are the lack of tourist attractions that are offered, poorly managed, the lack of parking spaces, and the lack of development. It is clear that the role of stakeholders is needed, both from the local community, government and the private sector in oder to develop an attractive tourist attraction in Gundaling Hill.

Keywords: Development of Tourist Attractions, Tourism Potential, Tourist Attraction.

\section{PENDAhUluan}

Dampak dari penemuan daya tarik wisata baru di berbagai daerah di Indonesia mengakibatkan turunnya angka kunjungan wisatawan dan kurangnya perhatian terhadap daya tarik wisata yang tergolong sudah lama, padahal daya tarik wisata tersebut masih sangat berpotensi untuk menarik wisatawan berkunjung ke daerah tujuan wisata tersebut.

Di Dataran Tinggi Karo dapat ditemukan indahnya nuansa alam pegunungan dengan udara yang sejuk dan yang berciri khas daerah penghasil buah dan sayur. Udara di Kota Berastagi yang sejuk serta pemandangan alam yang masih asri yang menjadi daya pikat utama Kawasan tersebut, dari Bukit ini pengunjung juga disuguhi pemandangan Gunung Merapi Sinabung, Gunung Merapi Sibayak dan Kota Berastagi sendiri yang berada persis dikaki Bukit ini. Menunggang kuda, naik delman mengelilingi kawasan Bukit dan kota Berastagi, menikmati kuliner dan melakukan wisata belanja, merupakan beberapa contoh kegiatan wisata yang dapat dilakukan oleh wisatawan yang berkunjung.

Seiring berjalannya waktu dan perkembangan jaman, Bukit Gundaling tidak lagi menarik bagi wisatawan. Ditemukan pula daya tarik wisata lain yang lebih menarik di Kabupaten Karo, seperti Palaruga dan Air Terjun Dua Warna. Perlu dilakukan pengembangan agar kunjungan wisatawan ke Bukit Gundaling meningkat dan dapat menjadi sumber pemasukan bagi masyarakat sekitar dan pemerintah daerah.

\section{TINJAUAN PUSTAKA}

\section{1 Konsep Potensi Wisata}

Menurut Pendit (1999) potensi wisata adalah berbagai sumber daya yang terdapat di sebuah daerah tertentu yang bisa dikembangkan menjadi atraksi wisata. Potensi wisata dibagi menjadi tiga macam, yaitu potensi alam, budaya dan buatan/manusia.

\section{2 Konsep Pengembangan Pariwisata}

Menurut Yoeti (1997) pengembangan pariwisata perlu memperhatikan beberapa aspek, yaitu: wisatawan, transportasi, atraksi/obyek wisata, fasilitas, Informasi dan promosi, serta merumuskan kebijakan.

\section{METODE PENELITIAN}

Penelitian ini menggunakan data primer, yang dimana informasi yang diperoleh dari sumber-sumber bersifat primer, data yang didapatkan berupa hasil observasi di lapangan serta wawancara yang dilakukan terhadap informan, data tersebut adalah informasi tentang Bukit Gundaling yang di dapat dari Kepala Bidang Promosi Dinas Kebudayaan dan Pariwisata Karo dan data sekunder, yang mana informasi yang diperoleh tidak secara langsung dari responden melainkan data dari literatur atau buku perpustakaan, juga website yang 
memiliki informasi terkait daya tarik wisata Bukit Gundaling.

Jenis data yang digunakan dalam penelitian ini adalah data kualitatif, yaitu data yang tidak bernilai numerik atau nilainya bukan angka (Kusmayadi dan Sugiarto 2000). Data yang dicari adalah hasil wawancara meliputi potensi yang dimiliki Bukit Gundaling. Data kuantitatif adalah data yang berupa bilangan, nilainya bisa berubah-ubah, data tersebut yaitu data kunjungan wisatawan Bukit Gundaling tahun 2010-2015.

Analisis data dilakukan secara deskriptif kualitatif, data dianalisis secara terus menerus selama proses penelitian berlangsung dan akan di paparkan sesuai dengan kerangka pemikirian yang berlaku umum.

\section{HASIL DAN PEMBAHASAN}

Berikut adalah data kunjungan wisatawan ke Bukit Gundaling 5 tahun terakhir:

Tabel 1. Data Kunjungan Wisatawan

\begin{tabular}{|c|r|r|r|r|r|r|}
\hline BULAN & \multicolumn{1}{|c|}{2010} & \multicolumn{1}{|c|}{2011} & \multicolumn{1}{c|}{2012} & \multicolumn{1}{c|}{2013} & \multicolumn{1}{|c|}{2014} & \multicolumn{1}{|c|}{2015} \\
\hline Januari & 13,550 & 10,500 & 12,980 & 14,076 & 3,137 & 15,998 \\
\hline Februari & 12,000 & 12,250 & 10,050 & 8,078 & 2,383 & 10,282 \\
\hline Maret & 13,250 & 10,550 & 11,833 & 4,895 & 4,068 & 8,120 \\
\hline April & 9,400 & 8,800 & 11,672 & 8,903 & 5,249 & 7,153 \\
\hline Mei & 21,750 & 17,400 & 14,367 & 10,955 & 8,780 & 10,478 \\
\hline Juni & 19,500 & 20,500 & 10,332 & 9,775 & 6,893 & 6,500 \\
\hline Juli & 7,250 & 19,000 & 14,527 & 7,715 & 7,130 & 9,305 \\
\hline Agustus & 18,550 & 1,450 & 17,260 & 20,993 & 13,414 & 7,851 \\
\hline September & 10,000 & 34,000 & 9,763 & 4,315 & 6,984 & 5,709 \\
\hline Oktober & 8,050 & 13,500 & 9,288 & 3,710 & 3,357 & 4,054 \\
\hline November & 10,500 & 11,750 & 4,548 & 2,763 & 5,695 & 5,266 \\
\hline Desember & 16,35 & 10,500 & 4,585 & 2,140 & 10,773 & 8,359 \\
\hline TOTAL & 160,150 & 170,300 & 131,205 & 98,318 & 37,640 & 99,075 \\
\hline
\end{tabular}

Sumber: Dinas Pariwisata Kabupaten Karo, 2016

Seperti yang tertera pada tabel diatas, terjadi penurunan pengunjung di beberapa tahun, terutama jelas terlihat pada tahun 2013 faktor utama penyebab penurunan jumlah kunjunan ini adalah karena terjadinya bencana alam meletusnya gunung merapi Sinabung, yang mana Gunung ini merupakan salah satu pemandangan yang dapat dinikmati langsung dari atas Bukit Gundaling.

\subsection{Potensi Wisata}

Berdasarkan konsep potensi wisata menurut Pendit (1999), potensi wisata terbagi menjadi tiga bagian, yaitu:

\section{A. Potensi Alam}

Keindahan alam dari Bukit Gundaling itu sendiri dan pemandangan Kota Berastagi yang juga didukung oleh pemandangan Gunung Sinabung dan Gunung Sibayak yang masih aktif menjadi potensi alam yang paling utama. Yang menjadi permasalahan adalah ketika potensi alam tersebut menjadi rusak atau tercemar oleh sampah dan banyaknya kotoran kuda yang berserakan, jadi perlu ada pengembangan yang dilakukan dalam pengelolaan sampah dan kotoran kuda yang tentunya memberikan rasa ketidaknyamanan kepada wisatawan yang mengunjungi Bukit Gundaling.

\section{B. Potensi Budaya}

Kehidupan masyarakat karo yang masih kental akan kebudayanya merupakan salah satu potensi budaya yang beragam mulai dari Bahasa Karo, Tarian Karo, Lagu Karo, dan peninggalan sejarah masyarakat Karo. Ciri khas tersebut tidak akan dijumpai di tempat lain selain di Bukit Gundaling yang terletak di Kabupaten Karo ini. Dijalan saat menuju Bukit Gundaling wisatawan akan melewati sebuah tugu yang dinamakan Tugu Perjuangan, tugu ini merupakan lambang dari semangat juang nenek moyang yang dahulu ikut berperang melawan penjajah, di tugu ini wisatawan dapat melakukan kegiatan berfoto.

\section{Potensi Buatan}

Kabupaten Karo kaya akan pertunjukan seni dan dapat menghasilkan kain tenun yang merupakan khas budaya Karo yang biasa disebut Uis Gara dan Bekabuluh, ini dapat dijadikan atraksi wisata yang baru dan menarik apabila di pertontonkan dan di perjual-belikan di Bukit Gundaling.

\subsection{Strategi Pengembangan Daya Tarik Wisata}

Berdasarkan konsep pengembangsn pariwisata menurut Yoeti (1997), terdapat beberapa aspek penting yang perlu diperhatikan pengembangannya di Bukit Gundaling, yaitu: 


\section{A. Wisatawan}

Wisatawan yang mengunjungi Bukit Gundaling tentu datan dari berbagai daerah dengan berbagai karakteristik, perlu dilakukan pendataan wisatawan datang dari negara mana, usia, hobi, dan pada musim apa mereka melakukan perjalanan wisata.

\section{B. Transportasi}

Transportasi yang tersedia hingga saat ini adalah Bus atau Angkutan Kota dengan rute Medan - Kabanjahe (melewati Berastagi) sedangkan dari Berastagi menuju daya tarik wisata Bukit Gundaling masih terbatas jumlahnya. Jadi sebaiknya dilakukan pengadaan transportasi seperti shuttle bus yang khusus membawa wisatawan dari kota Berastagi menuju Bukit Gundaling, dan juga sebaliknya

\section{Atraksi}

Atraksi wisata alam merupakan andalan utama bagi daya tarik wisata Bukit Gundaling ini, alam tidak dapat terlepas dari kebersihan dan keindahan, maka dari itu untuk meningkatkan atraksi wisata alam yang ada di Bukit Gundaling sebaiknya dilakukan peningkatan kepedulian terhadap kebersihan lingkungan sekitar Gundaling, yaitu dengan menyediakan tempat sampah yang disebar di beberapa titik lokasi. Ini berguna agar wisatawan yang mengunjungi Bukit Gundaling tahu kemana dia harus membuang sampah, agar sampah tidak dibuang disembarang tempat apalagi di hutan yang ada bawah Bukit Gundaling. Dengan ini keindahan akan jelas terlihat dan kenyamanan pun tercipta. Tanah Karo juga memiliki begitu banyak atraksi budaya yang dapat menambah atraksi yang disuguhkan di Bukit Gundaling, mulai dari tarian, nyanyian dan cerita-cerita bersejarah yang sangat menarik. Dapat diadakan pentas seni yang menampilkan tarian khas daerah Karo, seperti: Tarian 5 Serangkai, Nuan Page, dan Gundala-gundala di lokasi sekitar Bukit Gundaling.

\section{Fasilitas}

Saat ini salah satu pelengkap fasilitas kegiatan wisatawan adalah adanya beberapa kedai kopi di sekeliling Bukit Gundaling dengan pemandangan alam yang indahnya yang menyediakan makanan ringan, kopi, dan teh. Namun ini masih terasa kurang karena tidak disertai makanan pokok seperti nasi dan lauk pauk khas Tanah Karo yang tentunya akan menambah sempurnanya kegiatan wisata yang dapat dilakukan di Bukit Gundaling. Jadi tidak hanya tempat atau bangunan restoran atau cafe yang lebih baik tapi juga disertai dengan menu kuliner khas daerah Tanah Karo

Di Kawasan Bukit Gundaling dapat ditemui hotel, home stay, dan villa sebagai tempat beristirahat bagi para wisatawan, namun penataan yang kurang baik menyebabkan lingkungan terlihat kumuh. Dengan dilakukannya penataan ulang, diharapkan akan lebih tertatanya bangunanbangunan hotel atau home stay yang sudah ada.

Kurangnya lahan parkir menjadi salah satu penyebab macet karena banyak wisatawan yang memarkirkan kendaraannya di pinggir jalan, yang membuat Kawasan Bukit Gundaling menjadi tidak teratur. Akan lebih baik jika disediakan lahan yang lebih luas agar parkir kendaraan dapat lebih teratur.

\section{E. Informasi dan Promosi}

Penggunaan blog dan website sudah baik dalam melakukan promosi keluar daerah, namun dibutuhkan informasi yang terus diperbaharui agar calon wisatawan dapat mengethui dengan pasti informasi mengenai Bukit Gundaling. Jaman sudah semakin berkembang, dibutuhkan teknik yang lebih terdepan dalam melakukan promosi dan pemberian informasi, misalnya dengan menggunakan media sosial seperti; facebook, twitter, dan instagram sebagai sarana untuk kembali memperkenalkan Bukit Gundaling sebagai daya tarik wisata di Kabupaten Karo, Sumatera Utara. Sebagai pelengkap diperlukan juga adanya tourist information di Kawasan Bukit Gundaling untuk memberi informasi seputar kegiatan dan rute perjalanan wisatawan yang mengunjungi Bukit Gundaling.

\section{F. Perumusan Kebijakan}

Pemerintah daerah yang berwenang selayaknya mulai merumuskan kebijakan-kebijakan baru yang bertujuan untuk pengembangan Bukit Gundaling, misalnya kebijakan dalam bekerjasama dengan pihak ketiga atau investor. 


\section{SIMPULAN DAN SARAN}

\subsection{Simpulan}

Berdasarkan hasil penelitian yang dilakukan, simpulan yang dapat ditarik adalah bahwa daya tarik wisata alam dan panorama lah yang, menjadi dayatarik utama bagi Bukit Gundaling tersebut dan juga potensi budaya yang dapat dikembangkan menjadi ciri khas wisata di Kabupaten Karo dan juga memiliki potensi buatan yang dapat dikembangkan menjadi atraksi yang baru dan menarik wisatawan untuk mengunjung Bukit Gundaling.

Perlu dilakukan pengembangan di beberapa sektor seperti; pendataan wisatawan, transportasi, atraksi wisata, fasiltas, informasi dan promosi, serta perumusan kebijakan oleh pemerintah daerah.

\subsection{Saran}

Berdasarkan hasil penelitian yang dilakukan adapun saran yang dapat diberikan adalah sebagai berikut:

1. Daya tarik wisata Bukit Gundaling perlu dibenahi di beberapa sektor, selayaknya pemerintah memperhatikan dan mulai merancang pengembangan yang bertujuan terciptanya kembali daya tarik Bukit Gundaling yang menarik minat wisatawan untuk berkunjung dan yang pada akhirnya juga menguntungkan bagi pendapatan daerah dan perekonomian masyarakat lokal. 2. Masyarakat lokal kiranya beramah-tamah kepada wisatawan dan menguasai bahasa asing agar dapat berkomunikasi dengan baik dengan wisatawan mancanegara. Dengan adanya peran serta masyarakat dalam pengembangan daya tarik wisata Bukit Gundaling, maka akan terlaksanalah kemajuan dan perkembangan pesat pada kawasan wisata ini. Masyarakat pun akan terbantu perekonomiannya.

Daftar Pustaka:

Dinas Kebudayaan dan Pariwisata Karo. Booklet. 2010. Berastagi: Dinas Kebudayaan dan Pariwisata Kabupaten Karo.

Kusmayadi \& Endar Sugiarto, 2000. Metodelogi Penelitian dalam Bidang Kepariwisataan. Jakarta: PT. Gramedia Pustaka Utama

Moleong, Lexy. 2004. Metodologi Penelitian Kualitatif. Bandung: PT Remaja Rodakarya.

Pendit, Nyoman S. 1999. Ilmu Pariwisata. Jakarta; Akademi Pariwisata Trisakti.
Yoeti, Oka A. 1997. Perencanaan dan Pengembangan Pariwisata. Jakarta: PT Pradnya Paramita. 